Article

\title{
Exploring the Nexus between Migration and Social Positions using a Mixed Methods Approach
}

\author{
Ingrid Tucci ${ }^{1, *}$, Joanna J. Fröhlich ${ }^{2}$ and Inka Stock ${ }^{2}$ \\ ${ }^{1}$ LEST_Institute for Labour Economics and Industrial Sociology, CNRS, Aix Marseille University, 13326 Aix-en-Provence, \\ France; E-Mail: ingrid.tucci@univ-amu.fr \\ 2 Faculty of Sociology, Bielefeld University, 33501 Bielefeld, Germany; E-Mails: joanna.froehlich@web.de (J.J.F.), \\ inka.stock@uni-bielefeld.de (I.S.) \\ * Corresponding author
}

Submitted: 14 August 2020 | Accepted: 8 October 2020 | Published: 18 February 2021

\begin{abstract}
Using a mixed methods approach, this article analyses the nexus between migration and social positions drawing on recent survey data on migrants who have arrived in Germany after 1994 from the Socio-Economic Panel (SOEP), as well as qualitative interviews with 26 respondents to the survey. Drawing on a Bourdieusian forms-of-capital approach (Bourdieu, 1986) and applying the method of Multiple Correspondence Analysis (MCA) to the SOEP survey data, we highlight two dimensions structuring the nexus between migration and social positions in Germany: (1) capital related to legal status and multiple migration and (2) (trans)national cultural capital. Through a cluster analysis based on the MCA results, we then identify and describe four profiles of migrants characterised by distinct configurations of cultural capital (social class background, education and linguistic skills before and after settlement), legal status (citizenship and status at migration), experiences of multiple cross-border movements and social positions: the 'foreign working-class,' the 'foreign middle-class,' the 'adapted German migrants,' and the 'young highly educated urbans.' The complementary analysis of the qualitative data allows us to go further in understanding some of the factors that may play a role in shaping migrants' social position(ing) in the four clusters. In particular, we show that resources such as determination and perseverance can be crucial for some migrants to counter structural constraints related to their legal status in transferring or accessing cultural capital, and that linguistic skills are also used by some migrants as a marker of social distinction.
\end{abstract}

\section{Keywords}

cultural capital; Germany; mixed methods; migrants; migration; mobility; social positions; SOEP; social stratification; symbolic capital

\section{Issue}

This article is part of the issue "Migration and Unequal Social Positions in a Transnational Perspective" edited by Thomas Faist (Bielefeld University, Germany).

(C) 2021 by the authors; licensee Cogitatio (Lisbon, Portugal). This article is licensed under a Creative Commons Attribution 4.0 International License (CC BY).

\section{Introduction}

The relationship between migration and social inequality is a complex one and migration literature has been able to demonstrate extensively that a range of factors influence the socio-economic incorporation of migrants into the country they settle in, e.g., education and language skills (Kogan, 2011), social networks (Wrench, Rea, \& Ouali, 2016), duration of stay and discrimination (van
Tubergen et al., 2004), national origin (Drinkwater, Eade, \& Garapich, 2009) and class (van Hear, 2014). One dominant pattern of the studies based on quantitative data is their interest in explaining outcomes such as labour market participation, looking at the effect of different migrants' characteristics. A more qualitative strand of research pays particular attention to the trajectories of migrants of a specific origin, their lives between 'here and there' (e.g., Nieswand, 2011; Nowicka, 2013) and 
their social position, but many single out only one part of the social hierarchy in which migrants are positioned at destination, i.e., the least privileged migrants in specific sectors of the labour market (e.g., Friberg, 2012; Parrenas, 2020) or highly skilled migrants (e.g., Favell, 2008; Weiss, 2005).

Only a few empirical studies take a more 'global' perspective by looking at how different types of spatial mobility (experiences of living in several countries, legal status, etc.) and the individual resources migrants had before migrating (education, class background, language skills) structure migrants' social space, understood as the "space constructed on the basis of principles of distribution and differentiation" (Bourdieu, 1985, p. 724). Rare too are empirical studies that identify types or profiles of migrants, not according to their country of origin as is frequently done in research, but according to a set of social and cultural characteristics as well as characteristics related to the kind of migration they experienced. By this, we mean the legal, economic and social characteristics of people involved in cross-border movements, as well as the specific transnational spaces that migrants are embedded in through movement. We assume that these different types of migrants are characterised by distinct social positions in the destination society. Our approach allows us to account for the 'combination' (Vandebroeck, 2018, p. 363) of different forms of heterogeneities among migrants and resources or constraints related to cross-border movement and to think in terms of social differentiation.

Drawing on a mixed methods project, we use recent survey data on migrants who have arrived in Germany after 1994 from the Socio-Economic Panel (SOEP), as well as qualitative interviews with migrants who were also respondents in the survey. Using the method of Multiple Correspondence Analysis (MCA) we investigate which dimensions shape what we call the space of migrants' social positions, i.e., the space structured by characteristics related to migration and to diverse resources, in particular cultural capital (Bourdieu, 1986). Hierarchical clustering based on the MCA results allows us to identify four profiles of migrants characterised by different configurations of heterogeneities and social positions: the 'foreign working-class,' the 'foreign middle-class,' the 'adapted German migrants,' and the 'young highly educated urbans.' The mixed methods design we use has at least two advantages: It allows us (1) to link a 'global' perspective on social differentiation among the migrant population with more fine-grained information on cases and (2) to overcome the gaps of quantitative surveys that only provide minimal information about migrants' strategies, their aspirations, their resources and the obstacles they encountered.

The article is divided into four parts. After a presentation of the state of the art and the theoretical framework, we present the data and methods. The third section is devoted to the quantitative findings, in particular to the description of the central lines of differentiation characterising the population of concern and of the four profiles of migrants identified. In the last part, the qualitative data is used to analyse how individuals in each profile achieved their social position in Germany, with a focus on opportunities, constraints and individual strategies in transferring education and accessing training in Germany. In addition, we draw on the qualitative material to show the meaning of language proficiency for social positioning and social distancing.

\section{State of the Art and Theoretical Framework}

The research questions pursued in this article address the link between migration and social positions at destination, and in a broader sense between spatial mobility and social stratification. Spatial mobility is a complex concept that has led to various discussions and debates and can be thought of in various ways following different theoretical or disciplinary considerations (Kaufmann, 2017; Scholten \& van Ostaijen, 2018). Following Moret (2017), we consider mobility as "an element of social differentiation" (p. 2). Migrants are, by definition, mobile persons and their patterns of spatial mobility are diverse. Some leave their country of origin and settle directly in another country, while others have experienced multiple migration as well as settlement in several countries. While a strand of research centres its attention either on the least privileged migrants, highlighting the link between different mobility pathways and socio-economic mobility (on Filipino domestic workers see Parrenas, 2020) or the role of the 'work culture' assigned by the majority to a specific group (on Polish construction workers see Friberg, 2012), another strand of work focuses on highly skilled migrants, some of them being more privileged in their options to move (Favell, 2008) but not always in social positions at destination that correspond to their level of qualification (Weiss, 2005). Some authors have highlighted the status paradox some migrants experience when they gain prestige in the origin country by being looked at as successful migrants and, at the same time, loose social standing as immigrants in the destination country (on Ghanaian migrants see Nieswand, 2011). In this article we adopt a 'global perspective' for the analysis of the link between spatial mobility and social positions. We do not focus on a group of migrants with a particular geographical origin or social position at destination; instead, we account for the diversity of the internationally mobile population, as far as possible, with the aim of identifying which combination of characteristics related to cross-border migration and forms of capital (in particular cultural and symbolic capital) structures migrants' social positions, contributing to a socially stratified migrant population.

Many empirical studies in migration research mobilise Bourdieu's (1986) approach to capitals in order to draw out how structural forms of inequality like class, together with individual resources, like social networks, come to form peoples' position in social hierarchies (see, for example, Oliver \& O’Reilly, 2010; Ryan, Erel, \& 
D'Angelo, 2015). A large body of research focuses on the significance of cultural capital, such as formal education (Weiss, 2005) and the process through which migrants can or cannot acquire valuable cultural capital like formal education or language skills (Erel, 2009). The transferability of cultural capital in the country of destination is the aspect that has received the most attention in research on migrants' positioning on the labour market. Here, researchers have identified the strategies used by migrants to transfer cultural capital (Koikkalainen, 2014) or signalled the importance of perseverance and support from family and friends when looking for professional opportunities (Nohl, Schittenhelm, Schmidtke, \& Weiss, 2014). For their part, Nee and Sanders' (2001) concept of migrants' 'human-cultural capital' enlarges the perspective on cultural capital to other human competences related to migration such as host destination language proficiency. Many works indeed provide evidence on the influence of language skills on labour market outcomes (e.g., Kogan, 2011; Schuss, 2018). While most of the research looks at cultural capital in the form of qualifications or language skills, the role played by the embodied form of cultural capital, i.e., that constructed through the socialisation process in which class background plays a role (Bourdieu, 1986), is less researched. Recently, Engzell and Ichou (2020) showed that migrants' educational rank in the country of origin influences labour market outcomes at destination. But their study only considers education and not social background. This form of cultural capital, which is inherited through parental social class and determines the acquisition of "the valued characteristics that facilitate access to a range of social spaces and positions," has rarely been studied as an indicator for the social positions mobile persons occupy after moving (Cederberg, 2015, p. 36). As to language skills, they can be considered as institutionalized cultural capital due to the delivery of certificates to migrants after having passed the test following the integration course, for example, but also as a form of embodied capital where speaking "dialect-and accent-free German" is evaluated positively and plays a part in blurring social and ethnic boundaries. It is worth noting here that embodied cultural capital also includes practices, codes and norms that can have inclusionary or exclusionary effects in the settlement society (Cederberg, 2015, p. 33).

However, alongside the importance of cultural, economic or social capital for migrants' social positions, the specificities of migration itself also influence mobile people's place in social hierarchies (Parutis, 2014). This is because migrants' administrative and legal status at arrival influences the public perception of the group they are assigned to (Schmidtke, 2013) as well as their ability to negotiate the value of their cultural capital (Erel, 2010). EU migrants benefit from free movement and their cultural capital (their credentials, their language of origin or their practices) tends to be valued positively, depending also, however, on the national origin as shown by Basilio, Bauer, and Kramer (2017). Resettlers were grant- ed German citizenship once they had migrated back to Germany and benefited from specific aid and integration programmes (Groenendijk, 1997). Other migrants have more constraints, so that we can argue that the degree and type of capital created through moving also depends on the migration status at entry, on the context of origin, and on the regulations related to administrative status at destination. Migrants from a range of middleand low-income countries outside the European Union have limited opportunities to access a German visa that allows them to work and settle in the country, often also due to their limited economic resources and the devaluation of the specific forms of cultural capital they bring with them (e.g., origin language, diplomas). Thus, migration status can be analysed in Bourdieu's terms as symbolic capital that acts as "a signal that may trigger discrimination" (Gerhards, Hans, \& Drewski, 2018, p. 674) or have inclusion effects. In Bourdieu's sense, symbolic capital is thus a mechanism able to (de)value other forms of capital (Erel, 2009, 2010; Huot, 2017) because it depends on classification schemes operating in the destination country and on the judgement of others who have incorporated these schemes (Bourdieu, 1994, p. 161). Consequently, the type of mobility individuals experience in terms of legal migration and settlement status also influences the type of symbolic capital they are endowed with, and impacts on how their cultural capital and other skills can be transferred and will be judged.

We consider symbolic capital as a key concept when analysing migrants' social positions. Citizenship, religion and language, for example, have become central markers of ethnic boundaries in Germany (Zolberg \& Woon, 1999). As such, they not only shape objective opportunities and constraints, but may also express themselves in practices of symbolic boundary making (Lamont \& Molnár, 2002), creating social boundaries that include and exclude migrants from certain ethnic origins or on the basis of their migration status. In this article, we look at the combined effect of cross-border movement and citizenship status (as expressions of symbolic capital) and migrants' cultural capital (as expressed in formal education, class background and linguistic skills) on the social differentiation among the migrant population.

\section{Data and Methods}

The article is a mixed methods study involving quantitative analyses based on the IAB-SOEP Migration Sample, focusing on migrants who arrived after 1994 and 26 qualitative interviews with SOEP respondents (for more details see Supplementary File 1 and Sienkiewicz, Tucci, Barglowski, \& Faist, 2017). The data analysed is that of the year 2015 ( $N=1945$ respondents): 43\% of all respondents were born in Poland, Russia, Kazakhstan or Romania, $15 \%$ are resettlers, $38 \%$ were EU citizens when they migrated to Germany, $8 \%$ arrived as asylum seekers and $40 \%$ are classified as 'other foreigners.' This last category groups migrants from non-EU countries (69\%) or 
who arrived before their country became an EU member state (31\%). The survey data is linked with the qualitative interviews through a consented record linkage.

MCA is an appropriate analysis method for our research aims because its epistemological anchoring is not probabilistic but instead follows the information provided by the data (Le Roux \& Rouanet, 2010, p. 2). As a form of principal component analysis applied to categorical data, it aims to explore and summarise data in order to identify respondents with similar answers and the information most structuring the population of interest. The theoretical foundation for this approach is the idea that migration-related heterogeneities are not ran- domly distributed within the migrant population but rather structured by different dimensions to be discovered using MCA. The MCA results, i.e., the ten first dimensions structuring the data, are then used, as continuous factors, to perform hierarchical clustering in order to identify clusters or profiles of individuals based on similarities and distances between them from a multidimensional perspective (Husson, Lê, \& Pagès, 2017).

In MCA, active variables contribute to the construction of the dimensions structuring the data. The choice of the included variables is grounded on our exploratory analyses of the qualitative interviews as well as on our theoretical approach (see Table 1). Those vari-

Table 1. Variables included in MCA.

\begin{tabular}{|c|c|}
\hline Active & Supplementary \\
\hline Type of migration & Sex \\
\hline Resettlers, Eastern Europe & Marital status \\
\hline EU citizens & Partner/married \\
\hline Refugees, asylum seekers & Single \\
\hline Other foreigners & Age \\
\hline Migration experience & $18-35$ years \\
\hline Single & $36-45$ years \\
\hline One transit country & $46-55$ years \\
\hline Multiple migration & 56 years and more \\
\hline German citizenship & Immigration year \\
\hline No & EGP \\
\hline Yes & Service position \\
\hline Highest educational level father & Routine non-manual workers \\
\hline No vocational/university & Skilled workers \\
\hline Vocational & Non-skilled workers and agricultural workers \\
\hline University & Monthly household equivalent income \\
\hline \multicolumn{2}{|l|}{ Highest educational level mother } \\
\hline \multicolumn{2}{|l|}{ No vocational/university } \\
\hline \multicolumn{2}{|l|}{ Vocational } \\
\hline \multicolumn{2}{|l|}{ University } \\
\hline \multicolumn{2}{|l|}{ Education level } \\
\hline \multicolumn{2}{|l|}{ General elementary } \\
\hline \multicolumn{2}{|l|}{ Middle vocational } \\
\hline \multicolumn{2}{|l|}{ Vocational + A-Level } \\
\hline \multicolumn{2}{|l|}{ Higher education } \\
\hline \multicolumn{2}{|l|}{ Region of origin } \\
\hline \multicolumn{2}{|l|}{ Rural area/small town } \\
\hline \multicolumn{2}{|l|}{ Medium) city } \\
\hline \multicolumn{2}{|l|}{ Place of education } \\
\hline \multicolumn{2}{|l|}{ Germany } \\
\hline \multicolumn{2}{|l|}{ Abroad } \\
\hline \multicolumn{2}{|l|}{ Current German proficiency } \\
\hline \multicolumn{2}{|l|}{ Very good } \\
\hline \multicolumn{2}{|l|}{ Good } \\
\hline \multicolumn{2}{|l|}{ Fair } \\
\hline \multicolumn{2}{|l|}{ Poor/not at all } \\
\hline \multicolumn{2}{|c|}{ German proficiency before moving to Germany } \\
\hline \multicolumn{2}{|c|}{ 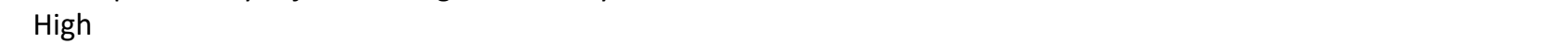 } \\
\hline \multicolumn{2}{|l|}{ Low } \\
\hline None & \\
\hline
\end{tabular}


ables relate to migration-specific legal-administrative and socio-cultural heterogeneities. Parental education is included as a form of pre-migration cultural capital. Supplementary variables do not contribute to the construction of the axes. We use them to assess whether certain categories of respondents share specific sociodemographic characteristics. Our focus here is on social positions that are operationalised using the EriksonGoldthorpe-Portocarero (EGP) class scheme reflecting their current or former occupational position (see Supplementary File 1) as well as using monthly equivalent household income. Summary descriptive statistics of the sample are available in Supplementary File 2.

The mixed methods design of the article is a fully mixed sequential dominant status design (Leech \& Onwuegbuzie, 2009) in which the quantitative findings are given more weight. The analysis of the 26 qualitative interviews complements and deepens the quantitative findings. It enables us, among other things, to show how individuals deal with structural or legal constraints to position themselves socially, i.e., to look also at strategies of social positioning, which is hardly feasible with quantitative data.

\section{Dimensions Structuring the Space of Migrants' Social Positions}

Cultural capital is unequally distributed within the mobile population. We want to analyse how this form of capital, together with legal-administrative heterogeneities, structures the migrant population that has arrived in Germany since the mid-1990s and whether groups of migrants sharing similar characteristics and social positions can be identified. Figure 1 shows how the modalities of the active variables are distributed in terms of coordinates on the first two identified axes that are the most relevant for the emerging data structure. For example, respondents who have experienced multiple migration in their life are located on the right, positive side of the horizontal axis and on the negative side of the vertical axis.

If we pay attention to the first two axes identified though MCA (see Figure 1 and Table 2), the first axis (horizontal) runs from those whose parents have no vocational or university degree to those whose parents have a university degree, as well as from those who originally came from smaller towns and rural areas to those from urban areas. In addition, the positive right side of the horizontal axis is characterised by individuals with a (very) good

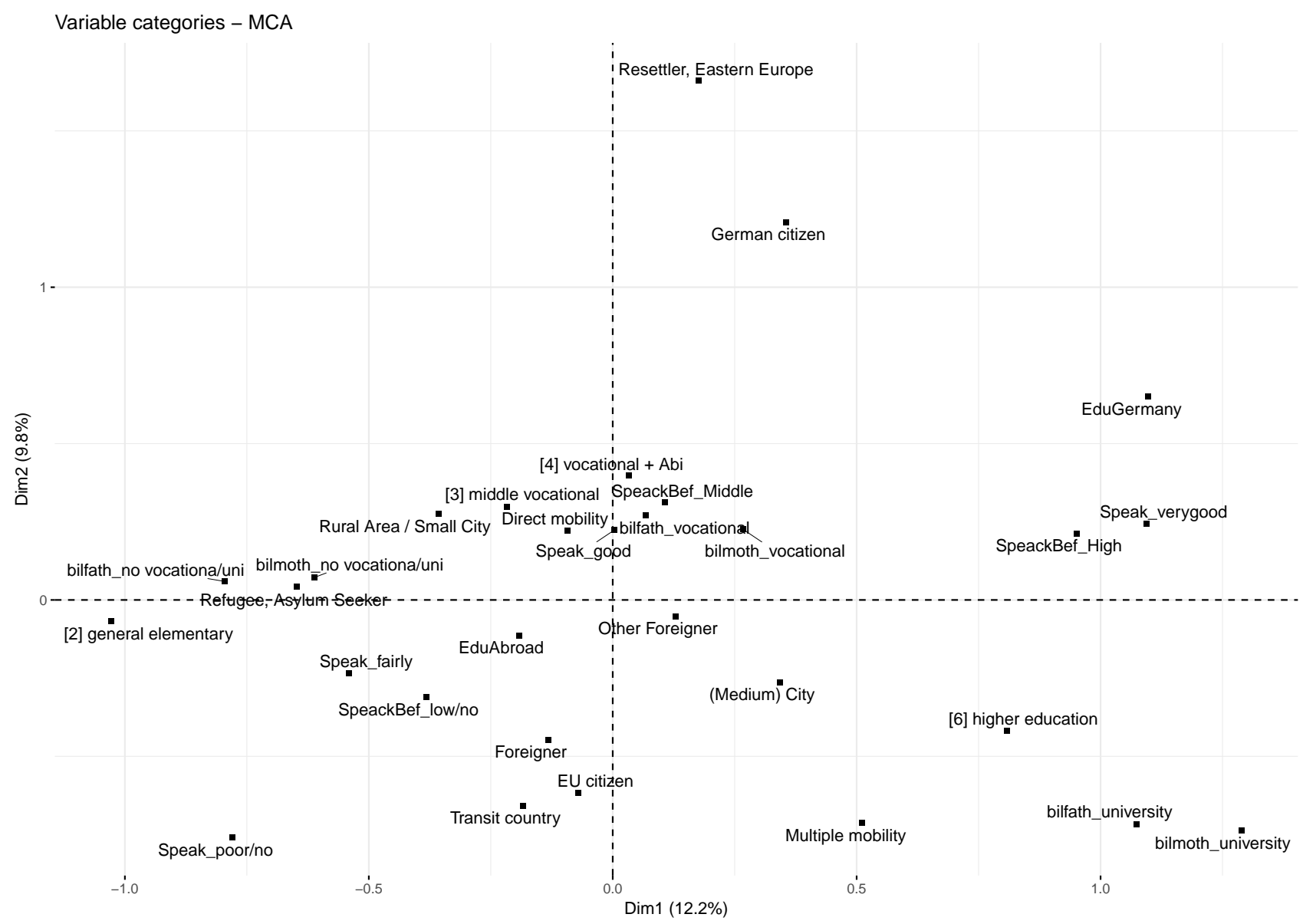

Figure 1. Variables' modalities on the two-dimensional space identified through MCA. 
Table 2. Contributions of the (active) modalities to the first two dimensions.

(Trans)national cultural capital

(horizontal-axis 1)

Negative side

German citizenship

Type of migration

German proficiency

Fair

Education mother

Education father

Own education

Region of origin

Experience of mobility

Place of education

German proficiency

before migration
Legal status and multiple migration (vertical-axis 2)

$\begin{array}{ll}\text { Negative side } & \text { Positive side } \\ \text { No } & \text { Yes } \\ \text { EU citizens } & \text { Resettlers }\end{array}$

Very good

University

University

University

University

Higher education

(Medium) city

Multiple migration

Germany

Germany knowledge of German before migration and being proficient in German at the time of the survey interview. This axis can be interpreted as an axis regarding the level of (trans)national cultural capital that migrants possess.

The second axis (vertical) runs from those, at the bottom, without German citizenship to those, at the top, who are Germans, as well as from individuals who came in the context of EU migration, from highly educated families or those having experienced multiple migration (bottom) to those who came as resettlers or those who were educated in Germany. This axis can be described as legal status and multiple migration.

In our case, supplementary variables enrich the interpretation and enable linking the dimensions to social positions. The positive side of axis 1 groups significantly respondents working in service positions, those aged 18 to 45 and frequently women, while the negative side concentrates skilled and unskilled manual workers, typically men, and respondents aged 45 or older. On the positive side of axis 2 one can find respondents aged 45 or older, who are single; often they are in different types of social positions except in service positions that are located on the negative side of this axis. Here we find younger respondents, often partnered. Immigration year is only correlated, negatively, with axis $2(0.47)$, meaning that migrants arrived more recently are located on the negative side of this axis. Household income, our second variable measuring social position, is only significantly and positively correlated with axis 1 (0.31). At this stage, the results indicate a structuration of social positions towards the top of the social hierarchy through multiple cross-border movements, high cultural capital in different forms, and a favourable status as migrants who are EU citizens and immigrated more recently than other migrants.

\section{Profiles of Migrants and Social Positions}

A hierarchical cluster analysis based on the MCA results suggested a four-cluster solution (see Figure 2). Each cluster is described in the following.

\subsection{Cluster 1: The Foreign Working-Class (34\%)}

The (trans)national cultural capital dimension contributed negatively and significantly to the formation of this cluster. Three-quarters of respondents in this cluster migrated directly to Germany as 'Other foreigners' or as refugees/asylum seekers (see Table 3). Eighty percent of all sample respondents who came as asylum seekers belong to this cluster. Only $18 \%$ in this cluster are German citizens. Two-thirds could not speak German on arrival in Germany and only a very small proportion declared they spoke very good German (8\%). They came largely from low-educated families. Half of them have only elementary education and roughly one-third have a middle vocational degree. Men are more represented than women. Individuals in this cluster belong mostly to the working class: $47 \%$ are semi or unskilled manual workers (see Figure 3 ) and only $8 \%$ are in a service position. This cluster has the lowest monthly household income (1304 EUR) and 31\% of them live below the poverty level ( $60 \%$ of the median household income).

\subsection{Cluster 2: The Foreign Middle-Class (28\%)}

This cluster is characterised by a high proportion of migrants from EU countries and 'other foreigners.' They arrived on average in the year 2005 and 19\% experienced multiple migration before moving to Germany. They are on average younger than respondents in Cluster 1. 
Factor map

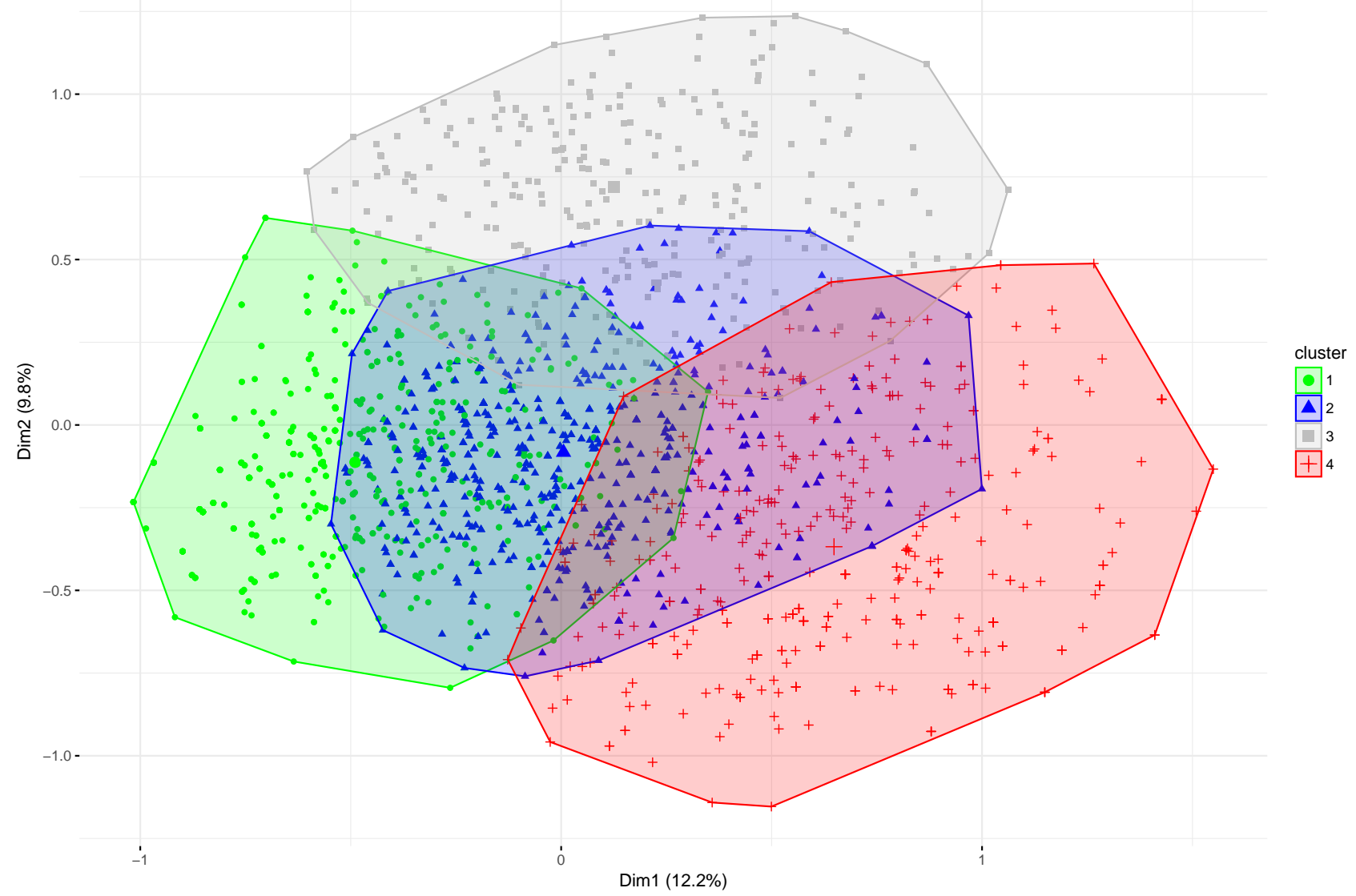

Figure 2. Cluster solution. Notes: Cluster 1 = 'foreign working-class,' cluster 2 = 'foreign middle-class,' cluster 3 = 'adapted German migrants,' cluster 4 = 'young highly educated urbans.' Source: SOEP (2019, survey year 2015).

German citizens are a minority among them (6\%). Their parents have on average a higher educational level than migrants in Cluster 1. 27\% of respondents reached higher education, $29 \%$ a high vocational degree. They mainly acquired their degrees outside Germany. Compared to respondents in Cluster 1 , they come often from urban areas, more often declared having a (very) good knowledge of German, also before they moved to Germany. In terms of social position, $24 \%$ had reached a service position but they are also numerous in unskilled manual and non-manual jobs. The mean household income is significantly higher than in Cluster 1 (1582 EUR) and 71\% of respondents have an income at the middle-class level for Germany (see Niehues, 2017).

\subsection{Cluster 3: The Adapted German Migrants (18\%)}

Dimension 2 (legal status and multiple migration) contributed positively and significantly to the formation of this cluster. Migrants in this cluster came mainly directly to Germany (91\%) and 93\% are Germans. Almost twothirds came as resettlers. Predominantly they live in a relationship (84\%, which is above average). Women and men are equally represented. The majority of their parents have a vocational education ( $62 \%$ of fathers and $46 \%$ of mothers) and they often come from rural areas (63\%). (Very) good German proficiency is a characteristic of this cluster (85\%); only $21 \%$ had no knowledge of German before migration. They have a slightly lower educational level than respondents in Cluster 2. One-third of them were educated in Germany or both in Germany and in the country of origin, which is also a characteristic of this cluster. $23 \%$ of them have reached a service position, and the proportion in skilled jobs is higher than for Cluster 2. Their income level and position are not significantly different from those of respondents in Cluster 2.

\subsection{Cluster 4: The Young Highly Educated Urbans (19\%)}

Dimension 2 contributed negatively and significantly to the formation of this cluster, while dimension 1 contributed positively. This group is composed mainly of 'other foreigners' (62\%) and EU citizens (30\%), coming from urban areas. $28 \%$ of respondents have multiple migration experiences ( $16 \%$ for the entire sample) and respondents without German citizenship are overrepresented (75\%). The gender ratio is nearly equal and the cluster consists of predominantly young people (half are aged 35 or younger). Their background is characterised by highly educated parents ( $78 \%$ have a father and $65 \%$ a 
Table 3. Description of the clusters (column percentages).

\begin{tabular}{|c|c|c|c|c|}
\hline & $\begin{array}{c}\text { Foreign } \\
\text { Working-Class }\end{array}$ & $\begin{array}{c}\text { Foreign } \\
\text { Middle-Class }\end{array}$ & $\begin{array}{l}\text { Adapted German } \\
\text { Migrants }\end{array}$ & $\begin{array}{c}\text { Young Highly } \\
\text { Educated Urbans }\end{array}$ \\
\hline \multicolumn{5}{|l|}{ Type of migration } \\
\hline Resettlers, Eastern Europe & 1.31 & 1.50 & 64.24 & 3.45 \\
\hline EU citizens & 21.22 & 48.47 & 2.56 & 29.80 \\
\hline Refugees, asylum seekers & 26.35 & 1.54 & 4.18 & 5.08 \\
\hline Other foreigners & 51.11 & 48.48 & 29.02 & 61.66 \\
\hline \multicolumn{5}{|l|}{ Migration experience } \\
\hline Direct to Germany & 80.49 & 71.84 & 91.33 & 62.96 \\
\hline One country before Germany & 6.97 & 9.23 & 2.87 & 9.36 \\
\hline Multiple migration & 12.54 & 18.93 & 5.80 & 27.68 \\
\hline German citizenship (Yes) & 18.16 & 5.68 & 93.20 & 25.31 \\
\hline \multicolumn{5}{|l|}{ Highest educational level father } \\
\hline No vocational/University & 74.58 & 5.57 & 30.11 & 9.57 \\
\hline Vocational & 16.62 & 88.02 & 62.47 & 12.89 \\
\hline University & 8.80 & 6.41 & 7.42 & 77.54 \\
\hline \multicolumn{5}{|l|}{ Highest educational level mother } \\
\hline No vocational/University & 95.50 & 26.31 & 47.80 & 20.24 \\
\hline Vocational & 3.91 & 71.19 & 46.32 & 15.15 \\
\hline University & 0.59 & 2.50 & 5.88 & 64.61 \\
\hline \multicolumn{5}{|l|}{ Education } \\
\hline General elementary & 54.06 & 8.29 & 12.79 & 0.33 \\
\hline Middle vocational & 30.19 & 35.96 & 38.15 & 11.12 \\
\hline Vocational + A-level & 5.29 & 28.84 & 25.53 & 5.22 \\
\hline University & 10.47 & 26.90 & 23.53 & 83.33 \\
\hline \multicolumn{5}{|l|}{ Place of education } \\
\hline Germany & 7.72 & 6.93 & 23.47 & 13.76 \\
\hline Abroad & 92.28 & 89.87 & 65.56 & 65.89 \\
\hline Both & 0.00 & 3.20 & 10.97 & 20.35 \\
\hline \multicolumn{5}{|l|}{ Region of origin } \\
\hline Rural area small town & 56.73 & 41.67 & 63.15 & 25.06 \\
\hline (Medium) city & 43.27 & 58.33 & 36.85 & 74.94 \\
\hline \multicolumn{5}{|l|}{ Current German proficiency } \\
\hline Very good & 7.77 & 16.17 & 35.63 & 45.68 \\
\hline Good & 41.20 & 45.65 & 49.54 & 34.03 \\
\hline Fair & 37.96 & 31.23 & 13.72 & 13.22 \\
\hline Poor/not at all & 13.07 & 6.95 & 1.11 & 7.07 \\
\hline \multicolumn{5}{|l|}{ German proficiency before moving } \\
\hline High & 6.46 & 9.90 & 23.94 & 25.86 \\
\hline Low & 27.62 & 43.45 & 55.09 & 40.18 \\
\hline None & 65.92 & 46.64 & 20.97 & 33.96 \\
\hline \multicolumn{5}{|l|}{ EGP } \\
\hline Service positions & 7.97 & 23.64 & 23.18 & 64.02 \\
\hline Routine non-manual workers & 18.78 & 27.26 & 22.91 & 21.37 \\
\hline Skilled workers & 22.96 & 15.79 & 24.12 & 8.46 \\
\hline Non-skilled workers & 50.29 & 33.31 & 29.78 & 6.16 \\
\hline Mean monthly household income (EUR) & 1304 & 1582 & 1561 & 2105 \\
\hline Percentage singles & 32.27 & 39.21 & 16.19 & 33.95 \\
\hline Percentage women & 37.43 & 46.43 & 54.12 & 44.11 \\
\hline Immigration year & 2000 & 2005 & 1999 & 2006 \\
\hline Mean age & 42 & 39 & 45 & 37 \\
\hline
\end{tabular}

Source: SOEP (2019, survey year 2015), weighted results. 
mother with a university degree). Migrants in this group are themselves also well educated ( $83 \%$ have a university degree). They declared they spoke (very) good German $(80 \%)$, and more than average (which is $14 \%$ ) spoke German before arriving in Germany (26\%). The dominant type of employment in this cluster is occupation in service positions: $29 \%$ are in higher and $35 \%$ in lower managerial positions (see Figure 3). They have the highest household income level (2105 EUR) and 28\% of them have more than $150 \%$ of the median household income so that they appear to be located in the upper (middle) class.

The presentation of the four clusters above highlights the heterogeneity of the migrants who have arrived since the mid-1990s in Germany in social and cultural terms. At the same time, respondents in each profile share characteristics that are significantly linked to social positions. Citizenship, social class origin and education are important criteria of social differentiation within this population. Multiple migration plays a role in all four clusters, though at different levels. The 'adapted German migrants' have the lowest and the 'Young Highly Educated Urbans' have the highest incidence of crossborder movements. Cluster 4 highlights the role played by multiple migration for higher social positioning when it is combined with high education levels. Nevertheless, multiple migration pays off for all respondents: a multivariate analysis we performed indicates that having lived in different countries before moving to Germany is signifi- cantly and positively correlated with being in skilled jobs, even after controlling for education and other relevant characteristics (see Table 2 in Supplementary File 2).

The four clusters are structured at the crossroads of different levels of (1) (trans)national cultural capital and (2) capital related to legal status and multiple migration. The qualitative interviews allow us to address these structuring dimensions for each profile in a more detailed manner, contributing with information on how migrants 'compose' their social position against the background of their cultural capital, structural opportunities, constraints, and related individual strategies.

\section{Understanding Migrants' Social Position(ing) further}

We were able to locate each participant in the qualitative study within the social and spatial mobility space designed with the MCA (see Figure 4) and to associate them with one of the four clusters: three respondents (FWC); seven respondents (FMC); five respondents (AGM); eleven respondents (YHEU). See also the Supplementary File 1 on the project methodology.

In the following we will focus on two aspects related to the structuring dimensions identified with the MCA: The first one deals with access to state support that some migrants benefit from due to their legal status on migration into Germany. The second one addresses how language skills contribute subjectively to social positioning and, at the same time, how they are used by

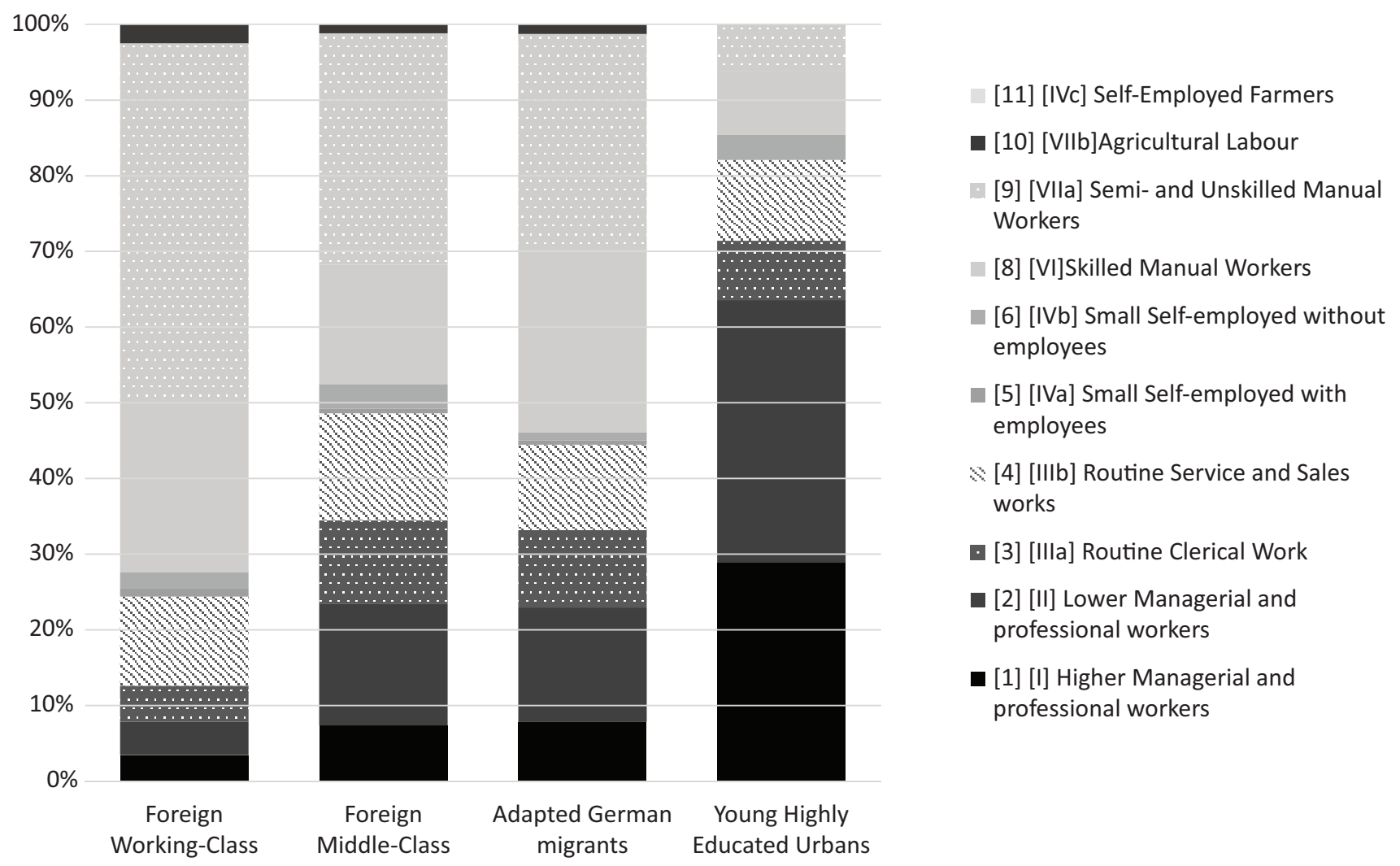

Figure 3. EGP by cluster. Source: SOEP (2019, survey year 2015), weighted results. 


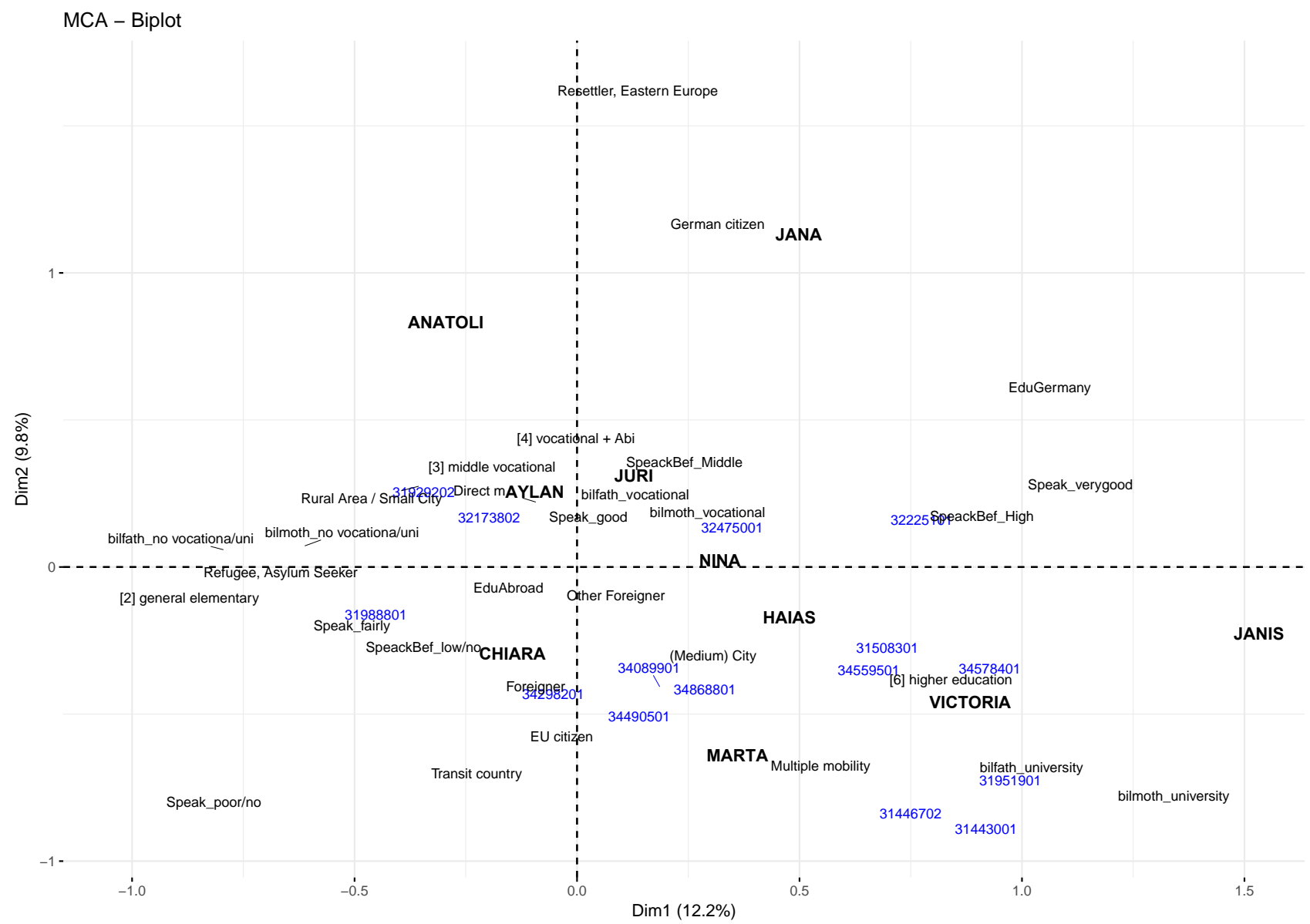

Figure 4. Positions of the 26 SOEP respondents. Source: SOEP (2019, survey year 2015).

migrants with multiple migration experiences and highly valued cultural capital to distance themselves from other migrants.

\subsection{Opportunities, Constraints and Strategies Transferring and Accessing Cultural Capital}

All respondents in the qualitative sample recognise that education is a valuable asset to secure a comfortable social position in Germany and that the ability to convert existing capitals into valuable resources in home and host countries is relevant. Between-clusters disparities as to the proportion of those working in the occupation they were trained for are significant: This concerns only a quarter of respondents in Cluster 1 (foreign workingclass), almost the majority of those in Clusters 2 (foreign middle-class) and 3 (adapted German migrants), and two-thirds of migrants in Cluster 4 (young highly educated urbans, see Figure 5). Interviewees in Clusters 2 and 3 differ only slightly in terms of social position (EGP and household income), despite the higher education level and social background of migrants classified as 'foreign middle-class' compared to 'adapted German migrants.'

The qualitative material tells us also that Clusters 2 and 3 differ in the opportunities, constraints and means migrants had to reach their social position in the mid- dle class in Germany. Due to their specific status, resettlers (who represent a large proportion of migrants in Cluster 3) got state support rapidly after their arrival, in the form of publicly funded training, language courses or adapted aid for the recognition of educational credentials (Groenendijk, 1997). This is the case for Juri and Anatoli (see Figure 4), who both came from Kazakhstan as resettlers. Juri was trained as a locksmith and received further specialised qualifications in Germany as a lathe operator and milling cutter. Anatoli for his part worked as a lorry driver in Russia but had a training as a painter in Germany. But state support does not guarantee an occupation in the field of training. Juri was never able to secure a stable job in his new training field and Anatoli never worked as a painter either but found stable employment in a fluids management company. In both cases, the job training did provide them with valuable German qualifications which were decisive when securing their future employment contracts, even if they did not match completely the work they were hired to do.

Those who came as resettlers at a relatively young age to Germany could successfully start university or vocational training after some years of schooling, as in the case of Jana who came at age 18 from Russia. She was encouraged by her teachers to pursue further studies when she arrived in Germany and this contributed to her 
80

70

60

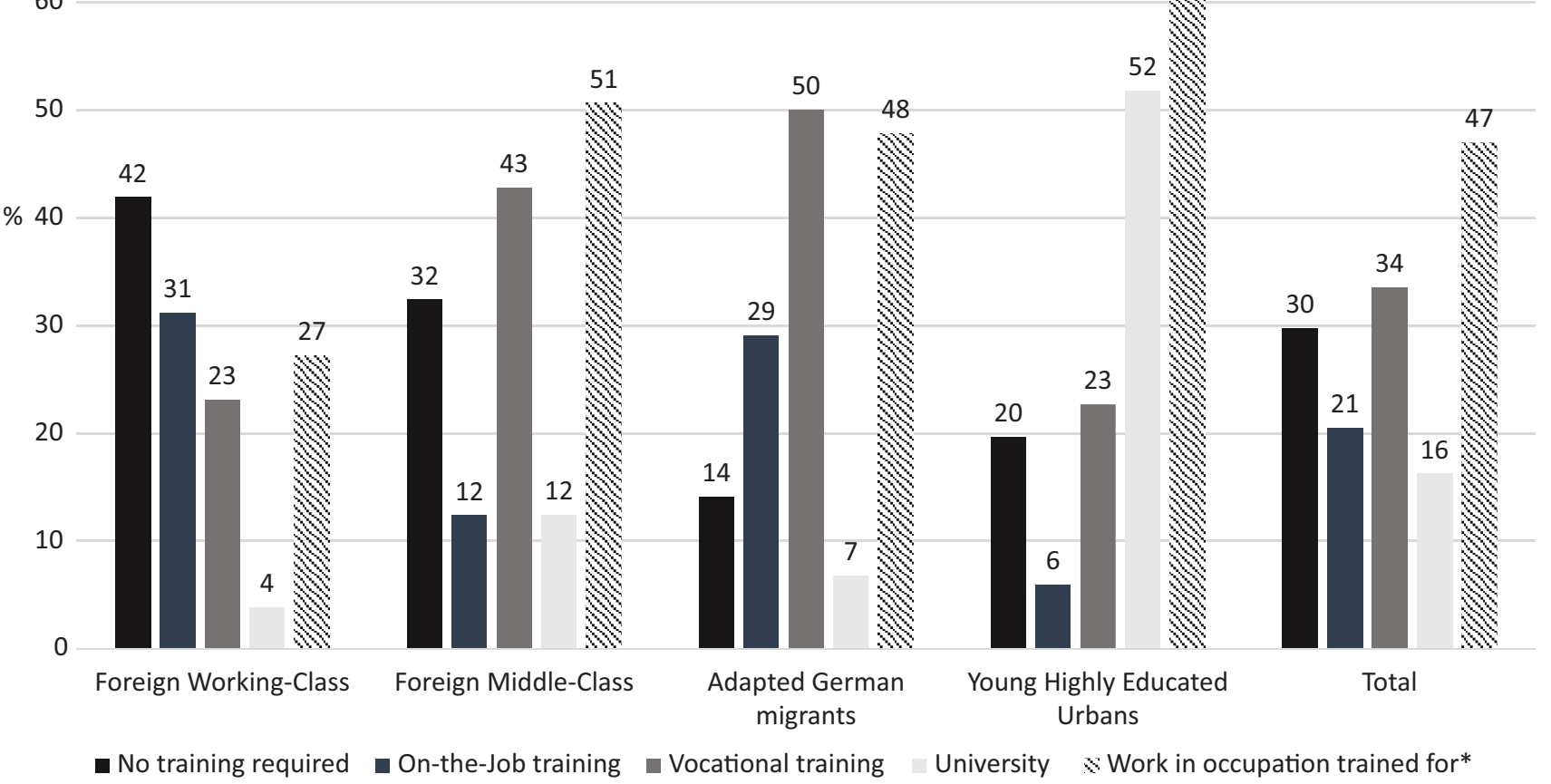

Figure 5. Training required and proportion of those with an occupation corresponding to training. Note: *only respondents with training. Source: SOEP (2019, survey year 2015), weighted results.

perseverance in learning German and excelling in school. She finally became a dental assistant although her excellent school grades could have enabled her to go to university and become a dentist. In her case, vocational training was described as having been a more secure career option than going to university and undertaking long and costly studies. She considered this a too risky alternative in light of the limited economic capital that she and her family possessed in the first years after migration. Family circumstances and preferences at some point in the life course also play a role in shaping social position after migration, in particular for women: In the interview, Jana explained that she considered several times taking up university in the years after her apprenticeship, but after having given birth to two children, she further postponed this wish, considering her family responsibilities incompatible with her wish for further qualifications. However, in contrast to other migrants in different clusters, Jana's narrative shows how she portrayed her professional and educational decisions as her own choice rather than the outcome of migration related, restricted opportunities.

In contrast to resettlers who were privileged in terms of obtaining work permits and residency status as well as state support upon their arrival in Germany right away, Aylan's story illustrates the type of obstacles some migrants face when they do not have these advantages. Aylan is of Turkish origin but he is a German citizen and belongs also to Cluster 3. He arrived in Germany aged 27, after completing military service and a tourism management degree at a Turkish university. He was not able to convert his degree into a corresponding degree or occupation in Germany and therefore asked the employment agency for financial support to undertake training as a specialist for warehouse logistics. In contrast to the resettlers, who appear to have received support often without greater problems, Aylan had to argue his case with determination in discussions with the employment agency official, who did not encourage his efforts in the slightest:

So I said, "Then I need to get a new qualification." "Oh," she says, "You can't do that so easily." Yes, that lady there. Then I was angry, and I said, "Please give me the number of your manager, or where can I find it?" After an hour or so, she says, "Come and make your application, it's approved."

Aylan's story is somewhat similar to that of some respondents in Cluster 2 who generally did not receive a great deal of state support. Chiara, for example, wanted to convert her economics degree from an Italian university into a suitable asset for the German job market. She paid for German courses in a private language school to bring her German skills up to standard. She also secured an internship in a human resources department with the help of 
contacts of her German husband in order to gain some German work experience. This enabled her to work for temping agencies before being able to get more stable job offers. She had in fact to wait for her first phase of unemployment to benefit from a training course in SAP management paid for by the employment agency which enabled her to later secure a job as a bookkeeper in an international firm.

It appears that determination and perseverance are an essential precondition to be successful in applications for state funded occupational support which is suitable for the specific career situation of the person in question. This is illustrated by Nina's example (Cluster 2 ). Nina was trained as office clerk in a South American country and could not get her diploma recognised in Germany. She began working in low skilled service jobs, among other things driving small school buses. When her contract expired, she had to negotiate the financing of her bus driver's licence at the employment agency. To do so, she decided to bring a declaration from her former employer stating that he would give her a new contract if she obtained the bus driver's licence:

Then I said, "But then I want it in black and white that I can work here again." Then he signed that declaration for me, and I went to the job centre and said, "Sorry, I'm unemployed now, these are the conditions, if I get my bus driver's license, if you help me pay for it, then can I work again and I don't have to have Daddy State on my pocket."

Nina's strategy of coming with proof that getting a bus driver's licence would enable her to get rapidly back to work and not take money from the state, like Aylan's determined strategy of refusing discouragement in achieving his goal and the devaluation of his learned ability, contrasts with the more systematic support resettlers received on their arrival in Germany. Also being a German citizen, as in Aylan's case, gives some confidence in asking for state support, which can be more difficult for nonGermans who might consider themselves illegitimate.

In Cluster 1, the 'foreign working-class,' we find respondents, mainly foreign citizens, who mostly work in unqualified jobs ( $42 \%$ do not require any training in their job, Figure 5). As seen in the quantitative part, many of them only have elementary education and come from families with a low social background. They often migrated directly to Germany. Irina for example is from Croatia. She came to Germany at age 18 , without any qualifications, fleeing the civil war in the 1990s and leaving her child with her family back in Croatia. She lost contact with her husband who had also fled. As her legal status was insecure for over eight years, she did not have any opportunity to ask for state support and worked mostly in bars, restaurants or bakeries to support her family back in Croatia. Her low wages and long working hours prevented her from taking German classes or vocational training. When she eventually married a German nation- al and became legally resident, she considered that any further occupational training would be useless as her level of German as well as her general level of formal education was simply not good enough to successfully obtain any vocational qualifications at her age.

The first three clusters contrast with Cluster 4, which has a high proportion of migrants working in occupations requiring tertiary education (52\%, Figure 5 ). Participants in the qualitative study belonging to this cluster were often trained in occupations which could often be undertaken by someone from anywhere in the world, e.g., software engineers, English teachers, translators, journalists, etc. In some cases, recognition of credentials and a licence are required to pursue a profession. This is the case of Janis, a man from Greece who came to Germany with very good knowledge of German and a psychotherapist's diploma: He engaged a lawyer to achieve this objective.

As we see here, different strategies are employed by migrants who do not benefit from a specific state support. Those strategies are strongly dependent on the resources migrants have before they move, on the necessity to start working rapidly or engaging in short vocational training to avoid a costly and long training, but also on the opportunities some of them have to use their knowledge of German and other languages as an asset to achieve objectives in terms of social position.

\subsection{Language Skills, Social Positioning and Social Distancing}

Similar to the 'adapted German migrants' (Cluster 3), a large proportion of the 'young highly educated urbans' (Cluster 4) declared they spoke very good German at the time of the SOEP interviews. Interestingly, the 'young highly educated urbans' tend to use language as a marker of distinction between themselves and other 'foreign migrants,' in particular newly arrived refugees or migrants whom some of them consider unwilling to adapt to their environment. Haias from Iraq is one of the few respondents who came as a refugee in Cluster 4. His father went to university and his mother has no qualification. After stopovers in Turkey and Greece, he arrived in Germany in 1995 and later obtained permanent status. Like many other interviewees in this cluster, he considers language central for social positioning and social mobility ("key to every success") and distances himself from newly arrived refugees:

Some refugees think if they stay here, they can do everything without the language. But the thing is [laughs], it's a catastrophe if you think like that.

Language can also mark a boundary charged with the symbolic value of respect:

The most important thing for me was to learn the language. I can't understand some people I know here, 
foreigners who've been here longer and can't even put two sentences together and expect other people to make allowances for them. I couldn't do that, I think it is disrespectful. (Victoria)

High proficiency in German and, in many cases for members of Cluster 4, knowledge of a third language due to their experience of multiple migration, increases the already high cultural capital they possess, giving them also a dose of positive symbolic capital, a marker of distinction over 'other migrants.'

In contrast, migrants from Clusters 1 and 2 often have to invest a lot personally and financially (and this despite their lower economic capital on average) in learning German to reach a better social position and regret the obstacles in this domain. For some interviewees, lower proficiency in German fully explains their position in lower status jobs. This is the case of Marta, a young woman who arrived directly from Poland and who works as a sales worker despite her high education level in a totally different field:

Yes, I'm a sales worker, but it's due to the language, because I was trained as a social pedagogue.

Like Marta, many interviewees in Clusters 1 and 2 more frequently have to renounce occupations they were trained for because of their low German skills and the interviews indicate a strong investment in language learning which is often self-financed and 'improvised,' as Aylan's case illustrates:

You have to learn the language. I really stepped on the gas at home, four or five hours at home, I wrote, read aloud and later I took a German course, I paid for it, more than 1,500 DM.

Generally, non-European migrants wishing to obtain residency status or citizenship have to participate in an integration course upon arrival, which is funded by the state and seen as a measure to provide migrants with knowledge of the language and the basics of the German administrative, political, and cultural context. Some respondents stressed that these kinds of measures are insufficient and that a lot more personal initiative is required in order to be successful in Germany.

The qualitative data highlight that resources such as determination, perseverance and investment can be crucial for some migrants to counter structural constraints in transferring or accessing cultural capital and that strategies for reaching a subjectively adequate social position differ according to those resources. Also, while linguistic skills are determining for reaching a better social position, language is also a marker for distancing oneself socially from other migrants. This last point also emphasises the importance of symbolic capital for understanding the nexus between migration and social position(ing) at destination.

\section{Conclusion}

This article provides an analysis of the nexus between migration and social positions in a social differentiation perspective using a mixed methods approach. It shows that two main dimensions contribute to the social differentiation of the migrant population that has settled in Germany since the mid-1990s and before the most recent migratory flow of asylum seekers in 2015. The first dimension, (trans)national cultural capital, emphasises the role played by social class, education and linguistic skills. This supports the idea that migrants' social status before migration needs to be considered to understand post-migration outcomes (Engzell \& Ichou, 2020). Existing research gives evidence on the link between linguistic skills and social positions (Kogan, 2011; Schuss, 2018) and our findings add to this literature the role played by the linguistic capital migrants bring with them as they move. The second dimension, legal status and multiple migration, indicates a clear line of division between those who have German citizenship and those who are still in an administrative foreigner status as well as the role played by multiple cross-border movements for reaching high social positions.

The socio-economic profiles of migrants before migration and the cultural, social and economic contexts they live in shape their social positions at destination. Likewise, the type of migration also shapes social position in the destination country. The combination of those different forms of structural and individual heterogeneities leads to a social differentiation along four profiles of migrants characterised by distinct positions in the social hierarchy in terms of EGP and household income. The 'foreign working-class,' characterised by more insecure legal status, foreign citizenship, low social-class origin, low education and unqualified occupations form the largest migrant groups within the space of migrants' social positions in Germany. The 'foreign middle-class' and the 'adapted German migrants' seem to share social positions in the middle of the social hierarchy but, as the qualitative analysis indicates, the difference between them in terms of occupational level is related to the different opportunities they had in transferring or accessing cultural capital. Finally, even if we observe a clear distinction in terms of income and occupation between the 'young highly educated urbans' and the other three profiles, we cannot conclude that the 'young highly educated urbans' form a transnational upper class (Sklair, 2000). Like other studies (Agrawal, 2016; Szewczyk, 2016), our results show the potential benefits of multiple migration for social mobility and support the argument that multiple migration is a significant dimension for "middle-class distinction" (Scott, 2006, p. 1110). It pays off, independently of the educational level migrants have and of their social class. This finding contributes to the analysis of the role played by multiple migration among migrants located "in the middle" (Salamońska, 2017, p. 19), confirming the finding 
that mobility-related capital is not a privilege of highly skilled migrants but rather an asset that other types of migrants also use in order to maintain or upgrade their social standing (Moret, 2017; Parrenas, 2020).

Furthermore, multiple migration combined with a privileged social background leads to the formation of a profile of migrants with specific ways of positioning themselves in relation to other migrants who not only have lower educational levels but also fewer resources that are easily convertible in transnational spaces. In this respect, the 'Young Highly Educated Urbans' clearly distinguish themselves from the other three types of migrants, which might be explained by the pre-migration habitus they possess through their parents' and their own education. Only a few works have considered this aspect as constitutive of the pre-migration habitus that mobile persons bring with them to a new social space (Reed-Danahay, 2017). However, our contribution indicates that some migrants maintain the value of their premigration cultural capital. Their higher social class origin and educational qualifications are positive signals in the country of destination which confer positive symbolic capital. This is so despite their lack of German citizenship and may be related to the particular resources that this group of migrants acquires through multiple crossborder movements, such as adaptability to new cultural norms or some other features of a certain 'cosmopolitan habitus.' However, this hypothesis would need further investigation. Our qualitative data showed that language proficiency too should not only be seen as cultural capital that furthers socio-economic integration, but also as a source of social differentiation within the migrant population because it functions as a strong symbolic boundary marker that expresses itself in the devaluing assessments that highly educated migrants (and many Germans) make about 'other foreigners' with low German proficiency.

Finally, there is a need for further research on the transnational reproduction of social inequality, accounting for the multiple cross-border movements some migrants experienced before settling in a country, gender differences in this respect as well as the subjective meaning attached to these movements. Secondly, a new research step would be to locate the four profiles of migrants within the larger German social structure in order to link those findings to the issue of social stratification in German society. Finally, we are aware that the qualitative results presented here constitute a small piece in the jigsaw puzzle of factors that makes up the dynamics of the nexus between migration and social positions. Other aspects such as social networks, racism and discrimination (Wrench et al., 2016) certainly shape these dynamics and need to be looked at more closely.

\section{Acknowledgments}

We would like to thank the two anonymous reviewers for their helpful comment and also the partici- pants in the final project workshop, in particular Justyna Salamońska, for their insightful suggestions on an earlier draft. We also thank the University Data Platform of Aix Marseille University (PUD-AMU) and Nicolas Pech (Aix Marseille University) for their advice.

\section{Conflict of Interests}

The authors declare no conflict of interests.

\section{Supplementary Material}

Supplementary material for this article is available online in the format provided by the author (unedited).

\section{References}

Agrawal, S. K. (2016). Twice migrants in Canada: Who are they and how do they perform economically? Journal of International Migration and Integration, 17(3), 669-686.

Basilio, L., Bauer, T. K., \& Kramer, A. (2017). Transferability of human capital and immigrant assimilation: An analysis for Germany. Labour, 31(3), 245-264.

Bourdieu, P. (1985). The social space and the genesis of groups. Theory and Society, 14(6), 723-744.

Bourdieu, P. (1986). The forms of capital. In J. G. Richardson (Ed.), Handbook of theory and research for the sociology of education (pp. 241-258). New York, NY: Greenwood Press.

Bourdieu, P. (1994). Raisons pratiques. Sur la théorie de I'action [Practical reason: On the theory of action]. Paris: Seuil.

Cederberg, M. (2015). Embodied cultural capital and the study of ethnic inequalities. In L. Ryan, U. Erel, \& A. D’Angelo (Eds.), Migrant capital (pp. 33-47). London: Palgrave Macmillan.

Drinkwater, S., Eade, J., \& Garapich, M. (2009). Poles apart? EU enlargement and the labour market outcomes of immigrants in the United Kingdom. International Migration, 47(1), 161-190.

Engzell, P., \& Ichou, M. (2020). Status loss: The burden of positively selected immigrants. International Migration Review, 54(2), 471-495.

Erel, U. (2009). Migrant women transforming citizenship: Lifestories from Britain and Germany. Aldershot: Ashgate.

Erel, U. (2010). Migrating cultural capital: Bourdieu in migration studies. Sociology, 44(4), 642-660.

Favell, A. (2008). Eurostars and Eurocities: Free movement and mobility in an integrating Europe. Oxford: Blackwell.

Friberg, J. H. (2012). Culture at work: Polish migrants in the ethnic division of labour on Norwegian construction sites. Ethnic and Racial Studies, 35(11), 1914-1933.

Gerhards, J., Hans, S., \& Drewski, D. (2018). Global inequality in the academic system: Effects of national 
and university symbolic capital on international academic mobility. Higher Education, 76(4), 669-685.

Groenendijk, K. (1997). Regulating ethnic immigration: The case of the Aussiedler. New Community, 23(4), 461-482.

Huot, S. (2017). 'Doing' capital: Examining the relationship between immigrants' occupational engagement and symbolic capital. Migration Studies, 5(1), 29-48.

Husson, F., Lê, S., \& Pagès, J. (2017). Exploratory multivariate analysis by example using $R$. London and New York, NY: Chapman and Hall/CRC.

Kaufmann, V. (2017). Re-thinking mobility: Contemporary sociology. New York, NY: Routledge.

Kogan, I. (2011). New immigrants-Old disadvantage patterns? Labour market integration of recent immigrants into Germany. International Migration, 49(1), 91-117.

Koikkalainen, S. (2014). Strategies for transferring cultural capital: The case of highly skilled Finns in Europe. Finnish Studies, 17(1/2), 155-179.

Lamont, M., \& Molnár, V. (2002). The study of boundaries in the social sciences. Annual Review of Sociology, 28(1), 167-195.

Le Roux, B., \& Rouanet, H. (2010). Multiple correspondence analysis. London: Sage.

Leech, N. L., \& Onwuegbuzie, A. J. (2009). A typology of mixed methods research designs. Quality \& Quantity, 43(2), 265-275.

Moret, J. (2017). Mobility capital: Somali migrants' trajectories of (im)mobilities and the negotiation of social inequalities across borders. Geoforum. https://doi. org/10.1016/j.geoforum.2017.12.002

Nee, V., \& Sanders, J. (2001). Understanding the diversity of immigrant incorporation: A forms-ofcapital model. Ethnic and Racial Studies, 24(3), 386-411. vNiehues, J. (2017). Die Mittelschicht in Deutschland: Vielschichtig und stabil. [The middle class in Germany: Diverse and stable]. IW-Trends-Vierteljahresschrift zur empirischen Wirtschaftsforschung, 44(1), 3-20.

Nieswand, B. (2011). Theorising transnational migration: The status paradox of migration. New-York, NY: Routledge.

Nohl, A.-M., Schittenhelm, K., Schmidtke, O., \& Weiss, A. (2014). Work in transition: Cultural capital and highly skilled migrants' passages into the labour market. Toronto: University of Toronto Press.

Nowicka, M. (2013). Positioning strategies of Polish entrepreneurs in Germany: Transnationalizing Bourdieu's notion of capital. International Sociology, 28(1), 29-47.

Oliver, C., \& O'Reilly, K. A. (2010). Bourdieusian analysis of class and migration: Habitus and the individualizing process. Sociology, 44(1), 49-66.

Parrenas, R. (2020). The mobility pathways of migrant domestic workers. Journal of Ethnic and Migration Studies. Advance online publication. https://doi.org/ 10.1080/1369183X.2020.1744837
Parutis, V. (2014). 'Economic migrants' or 'middling transnationals'? East European migrants' experiences of work in the UK. International Migration, 52(1), 36-55.

Reed-Danahay, D. (2017). Bourdieu, social space, and the nation-state. Implications for migration studies. Sociologica, 11(2). https://doi.org/10.2383/88198

Ryan, L., Erel, U., \& D’Angelo, A. (Eds.). (2015). Migrant capital. London: Palgrave Macmillan.

Salamońska, J. (2017). Multiple migration: Researching the multiple temporalities and spatialities of migration (CMR Working Paper 102/160). Cologne: Center for Macroeconomic Research.

Schmidtke, O. (2013). Wasting newcomers' human capital? Cultural capital and the integration of skilled migrants into the British and German labor markets. In T. Triadafilopoulos (Ed.), Wanted and welcome? (pp. 287-304). New York, NY: Springer.

Scholten, P., \& van Ostaijen, M. (Eds.). (2018). Between mobility and migration. Cham: Springer.

Schuss, E. (2018). The impact of language skills on immigrants' labor market integration: A brief revision with a new approach. The BE Journal of Economic Analysis \& Policy, 18(4). Advance online publication. https:// doi.org/10.1515/bejeapp. 2017-0280

Scott, S. (2006). The social morphology of skilled migration: The case of the British middle class in Paris. Journal of Ethnic and Migration Studies, 32(7), 1105-1129.

Sienkiewicz, J. J., Tucci, I., Barglowski, K., \& Faist, T. (2017). Contrast Groups based on spatial mobility and social position for use in the qualitative sample. Technical report of the "Transnational mobility and social positions in the European Union" (COMCAD Working Paper No. 152). Bielefeld: COMCAD.

Sklair, L. (2000). The transnational capitalist class and the discourse of globalisation. Cambridge Review of International Affairs, 14(1), 67-85.

SOEP. (2019). Socio-economic panel, data from 1984-2017 (version 34) [Data set]. https://doi.org/ 10.5684/soep.v34

Szewczyk, A. (2016). Polish graduates and British citizenship: Amplification of the potential mobility dynamics beyond Europe. Mobilities, 11(3), 362-381.

van Hear, N. (2014). Reconsidering migration and class. International Migration Review, 48(1), 100-121.

van Tubergen, F., Maas, I., \& Flap, H. (2004). The economic incorporation of immigrants in 18 Western societies: Origin, destination, and community effects. American Sociological Review, 69(5), 704-727.

Vandebroeck, D. (2018). Toward a European social topography: The contemporary relevance of Pierre Bourdieu's concept of 'social space.' European Societies, 20(3), 359-374.

Weiss, A. (2005). The transnationalization of social inequality: Conceptualizing social positions on a world scale. Current Sociology, 53(4), 707-728.

Wrench, J., Rea, A., \& Ouali, N. (Eds.). (2016). Migrants, 
ethnic minorities and the labour market: Integration and exclusion in Europe. London: Palgrave Macmillan. Zolberg, A. R., \& Woon, L. L. (1999). Why Islam is like
Spanish: Cultural incorporation in Europe and the United States. Politics \& Society, 27(1), 5-38.

\section{About the Authors}

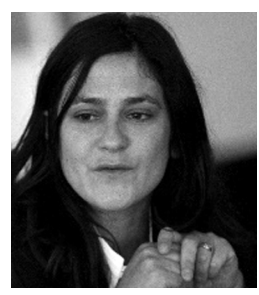

Ingrid Tucci is a Sociologist and a CNRS researcher at the Institute for Labour Economics and Industrial Sociology (LEST) at Aix Marseille University. She is interested in ethno-racial inequality at school and on the labour market and in international comparisons, with a focus on France and Germany. Her current research focuses on the life courses of migrants' descendants in Germany using mixed methods, and on ethnic boundary making strategies and reactions to discrimination.

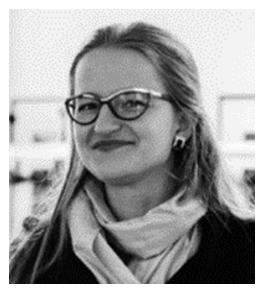

Joanna J. Fröhlich (née Sienkiewicz; PhD) is a Researcher in the project "Transnational Mobility and Social Positions in the European Union" funded by the German Research Foundation (DFG) at Bielefeld University. In her doctoral thesis (2017) she studied the social protection networks of migrants from Kazakhstan in Germany and their relatives in Kazakhstan. Her research interests include migration, social inequality and (transnational) research methods.

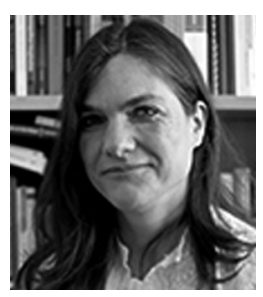

Inka Stock is a Post-Doctoral Researcher at the Centre on Migration, Citizenship and Development (COMCAD) at the Faculty of Sociology, Bielefeld University, Germany. She has a particular interest in the nexus between migration and inequality, migration and development and gender and migration. Her regional focus lies on migration in and from Africa. 